\title{
Creep behaviour of unreinforced and reinforced QE22 magnesium alloy: A comparison
}

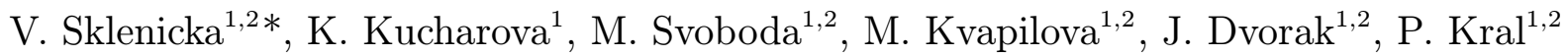 \\ ${ }^{1}$ Department of Mechanical Properties, Institute of Physics of Materials, Academy of Sciences of the Czech Republic, \\ 61662 Brno, Czech Republic \\ ${ }^{2}$ CEITEC - Institute of Physics of Materials, Academy of Sciences of the Czech Republic, 61662 Brno, Czech Republic
}

Received 23 January 2020, received in revised form 29 January 2020, accepted 5 February 2020

\begin{abstract}
A significant improvement in the creep properties of magnesium monolithic alloys at high temperatures can potentially be achieved through processing various magnesium metal matrix composites in which the matrix alloy is strengthened through the introduction of non-metallic fibres or particulates. In this work, a comparison between the creep behaviour and characteristics of an unreinforced high-strength creep-resistant QE22 matrix alloy and a QE22 alloy composite reinforced with $20 \mathrm{vol} \% \mathrm{Al}_{2} \mathrm{O}_{3}$ (Saffil) short fibres was performed. Constant stress tensile creep tests were carried out at 423,473 , and $523 \mathrm{~K}$, and the applied stresses ranged from 30 to $200 \mathrm{MPa}$. The creep strengthening of the composite by reinforcement arises mainly from effective load transfer between matrix and fibres provided that no extensive debonding of the fibre/matrix interfaces or substantial breakage of fibres during creep exposure occur. However, the beneficial effect of reinforcement and the improved creep resistance of the composite is significantly influenced by the creep loading conditions.
\end{abstract}

Key words: magnesium alloy, composite, creep, transfer load, fibre/matrix debonding, fracture

\section{Introduction}

The creep resistance of the most magnesium alloys is rather limited at temperatures above $373 \mathrm{~K}$ due to their low melting points [1]. However, a significant improvement in the creep properties of magnesium monolithic alloys can potentially be achieved through processing various discontinuous magnesium metal matrix composites, where matrices consist of conventional magnesium alloys that are strengthened through the introduction of non-metallic fibres, particulates, or both to form metal matrix composites (MMCs) [2-9]. In fact, an experimental study of the creep behaviour of AZ91 alloy reinforced with $20 \mathrm{vol} . \%$ $\mathrm{Al}_{2} \mathrm{O}_{3}$ short fibres and unreinforced AZ91 matrix alloy showed that using short alumina fibres is very effective in considerably improving the creep properties of squeeze-cast AZ91 monolithic alloy [6, 8].

It is now well established [8] that the creep of metal matrix composites is controlled by the rate of flow within the matrix alloys. Therefore, creep- -resistant precipitate strengthened magnesium QE22 alloy was selected for further attempts to clarify the creep strengthening mechanisms in its short fibre reinforced magnesium composite. QE22 alloy was derived from Mg-Re-Zr alloys by the addition of silver to improve its mechanical properties due to both strengthening effect of matrix precipitates and the presence of the grain boundary phases [6, 7]. Furthermore, it is assumed that an additional improvement of its creep resistance and thermal stability could be potentially achieved by reinforcement with $\mathrm{Al}_{2} \mathrm{O}_{3}$ short fibres by analogy with a previously studied reinforced AZ91 alloy $[6,8]$.

The present investigation was initiated to obtain a better understanding of the role of possible reinforcement by short fibres in magnesium alloys. This work reports a comparison of the experimental results obtained in an investigation of the high temperature creep properties of short fibre reinforced QE22 matrix composite and its matrix monolithic alloy, which were both produced by squeeze casting.

*Corresponding author: tel.: +420 532290 454; e-mail address: sklen@ipm.cz 


\section{Experimental materials and procedures}

Short-fibre reinforced and unreinforced blocks of high-strength silver-containing alloy QE22 (2.5 wt.\% $\mathrm{Ag}, 2.0 \mathrm{wt} . \% \mathrm{Nd}$ rich mixture of rare earth elements, 0.6 wt.\% Zr, balance $\mathrm{Mg}$ ) were produced by squeeze casting [1] at Technical University of Clausthal, Germany. The orientation of fibres in the preform was planar with randomly distributed $\delta-\mathrm{Al}_{2} \mathrm{O}_{3}$ short fibres, Saffil ${ }^{\circledR}\left(97 \% \delta-\mathrm{Al}_{2} \mathrm{O}_{3}, 3 \% \mathrm{SiO}_{2}\right)$. Saffil fibres were $\sim 3 \mu \mathrm{m}$ in diameter with varying lengths, up to an estimated maximum of $\sim 150 \mu \mathrm{m}$ measured after squeeze casting. The preforms consisting of $\mathrm{Al}_{2} \mathrm{O}_{3}$ short fibres and a binder system were preheated to a temperature higher than the melt temperature of the alloy and then inserted into a preheated die. The two-stage application of pressure resulted in a composite with an about 20 vol.\% final fibre fraction after squeeze casting. For convenience, the composite is henceforth designated QE22 + Saffil. After production, both unreinforced QE22 alloy and its composite were subjected to a T6 heat treatment. The mean grain size of the unreinforced QE22 alloy was estimated to be about $50 \mu \mathrm{m}$ and for the composite $\sim 9 \mu \mathrm{m}$.

Flat creep specimens with a $25 \mathrm{~mm}$ gauge length and $3 \times 3.2 \mathrm{~mm}^{2}$ cross-sections were machined from the blocks so that the longitudinal specimen axes were parallel to the plane in which the long axes of the fibres were situated. Constant stress tensile creep tests were carried out at temperatures from 423 to $523 \mathrm{~K}$ and at tensile applied stresses ranging from 30 to $200 \mathrm{MPa}$. The creep tests were performed in purified argon using tensile creep testing machines, making it possible to keep the applied stress constant to within $0.1 \%$ up to a true strain of about 0.35 [10]. The testing temperature was monitored during creep tests and maintained constant to within $\pm 0.5 \mathrm{~K}$. Almost all the tests were run to the final fracture of creep specimen. The creep elongations were continuously measured during the whole creep exposure using a linear variable differential transducer, W2K from Hottinger-Baldwin Co., Germany (the elongation was measured with a sensitivity of $5 \times 10^{-6}$ ), and they were recorded digitally, and computer processed.

Metallographic and fractographic investigations of creep specimens were conducted after creep testing using either a transmission electron microscope, Philips CM 12 TEM/STEM, or a scanning electron microscope, Tescan Lyra 3 XMU.

\section{Experimental results and discussion}

\subsection{Creep behaviour in the unreinforced and reinforced QE22 alloy}

The creep test results can be plotted as standard
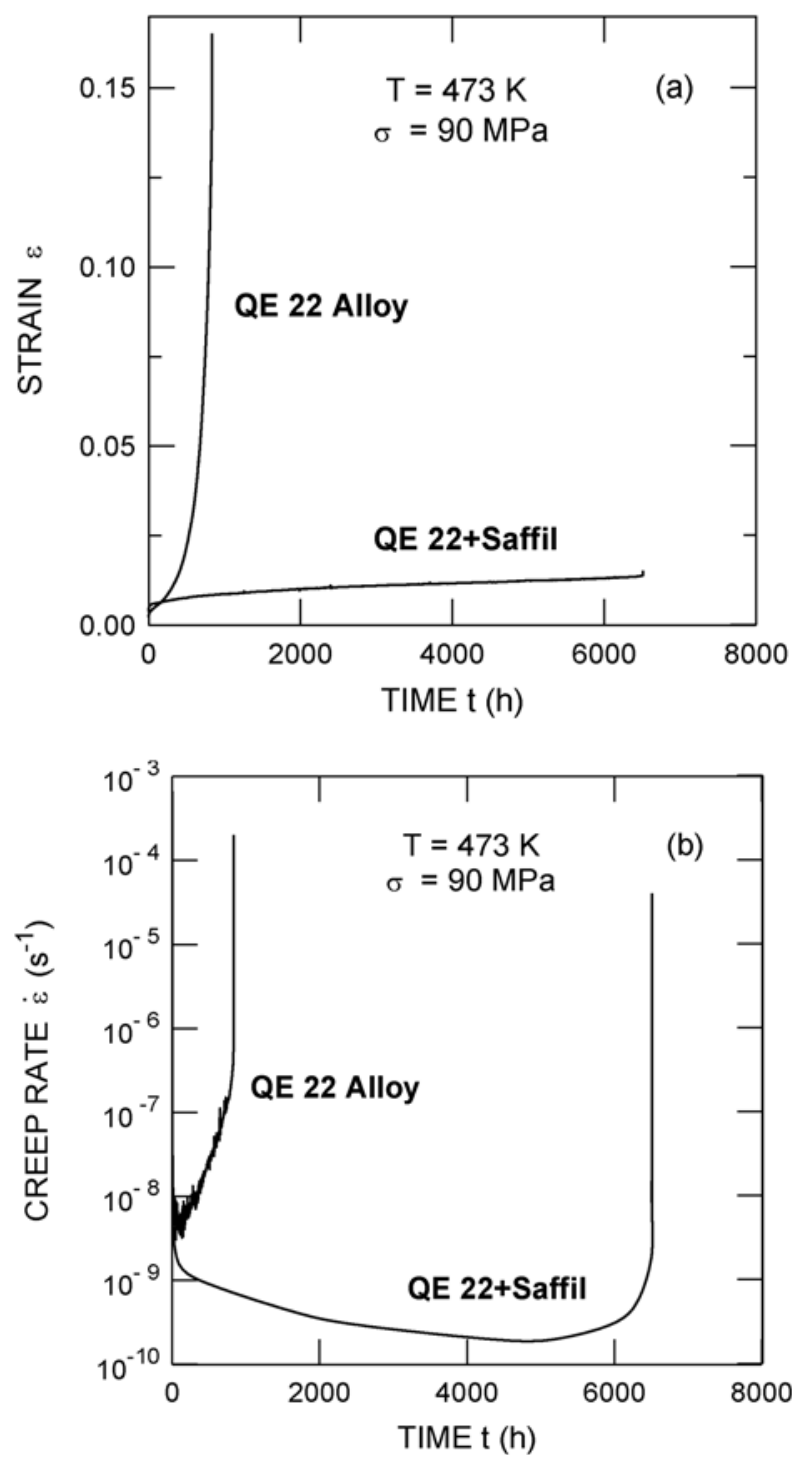

Fig. 1. Comparison of creep curves for QE22 alloy and QE22 + Saffil composite at $473 \mathrm{~K}$ and $90 \mathrm{MPa}$ (a) standard creep curve and (b) modified creep curve.

creep curves, which graphically represent the time dependence of strain, $\varepsilon$ (elongation), over a gauge length of the creep specimen. Representative standard creep curves, $\varepsilon$ vs. $t$, of the QE22 alloy and the QE22 + Saffil composite at $473 \mathrm{~K}$ and the same value of the applied stress, $\sigma=90 \mathrm{MPa}$, are shown in Fig. 1a. As demonstrated in Fig. 1a by the shapes of standard creep curves, significant differences were found in the creep behaviour of the composite when compared to its matrix alloy. Frequently, the standard creep curve of most materials can be described by four stages of creep, consisting of instantaneous strain, $\varepsilon_{0}$, just after loading the specimens and primary, secondary, and tertiary stages during creep exposure to the final fracture of the specimen. However, as is obvious from Fig. 1a, 
the following main differences in the behaviour of both materials can be observed. First, the presence of short fibre reinforcement leads to a significant decrease in the creep fracture strain (creep fracture plasticity), which is proved by the values of the total strain to fracture, $\varepsilon_{\mathrm{f}}$, for the composite. Second, the composite exhibits a markedly longer time to fracture, $t_{\mathrm{f}}$ (creep life), than the matrix alloy under the same loading conditions. Third, by contrast to the alloy curve, the composite curve shows the primary stage is fairly extensive. Fourth, a brief inspection of Fig. 1a suggests that the creep curve for the unreinforced alloy exhibits a sharp creep rate minimum very early after specimen loading.

It is obvious that the standard creep curves shown in Fig. 1a do not clearly indicate the individual stages of creep. Therefore, these standard $\varepsilon$ vs. $t$ creep curves can be replotted in a different coordinate system in the form of strain rate, $\dot{\varepsilon}$ vs. $t$, as shown in Fig. 1b. A dramatic difference is shown in the extent of primary creep, which is extremely short in the unreinforced alloy. In contrast, the primary stage in the composite is fairly extensive and practically covers the essential duration of the creep test. The decreasing creep rate in the primary creep stage can be attributed to strain hardening or a decrease in the density of mobile dislocations. From inspecting Fig. 1b, it is clear that neither curve exhibits a well-defined steady-state and this stage is reduced to an inflexion point on the $\dot{\varepsilon}$ vs. $t$ curve. In this case, the minimum creep rate, $\dot{\varepsilon}_{\mathrm{m}}$, can be defined instead of the steady-state creep rate, $\dot{\varepsilon}_{\mathrm{s}}$. The minimum creep rate, $\dot{\varepsilon}_{\mathrm{m}}$, can be explained by the process where hardening in the primary stage is balanced by softening in the tertiary stage. The increase in creep rate with time in the tertiary creep stage can follow from microstructure instability and evolution, which reflects the effect of plastic strain on the microstructure softness. As can be seen from Fig. 1b, the softness development during the tertiary creep of both materials significantly differs from each other. Necking of the specimens, which could cause a significant increase in the applied stress and thus an increase in the creep rate exhibited in the tertiary creep stage of the composite, can be omitted during the constant-stress creep testing used in this work.

From Fig. 1, it is apparent that the creep resistance of the composite can be significantly improved compared to the unreinforced alloy. However, it cannot be excluded that the creep behaviour and resulting creep properties of both materials could strongly be influenced by the creep loading conditions used. In fact, it is apparent from Fig. 2, which shows the creep behaviour of both materials at the same temperature but at increased applied stress only up to $\sigma=100 \mathrm{MPa}$. In a striking difference between Figs. 1 and 2, Fig. 2 shows an essential deterioration of the creep resistance of the composite compared to monolithic alloy. Thus,
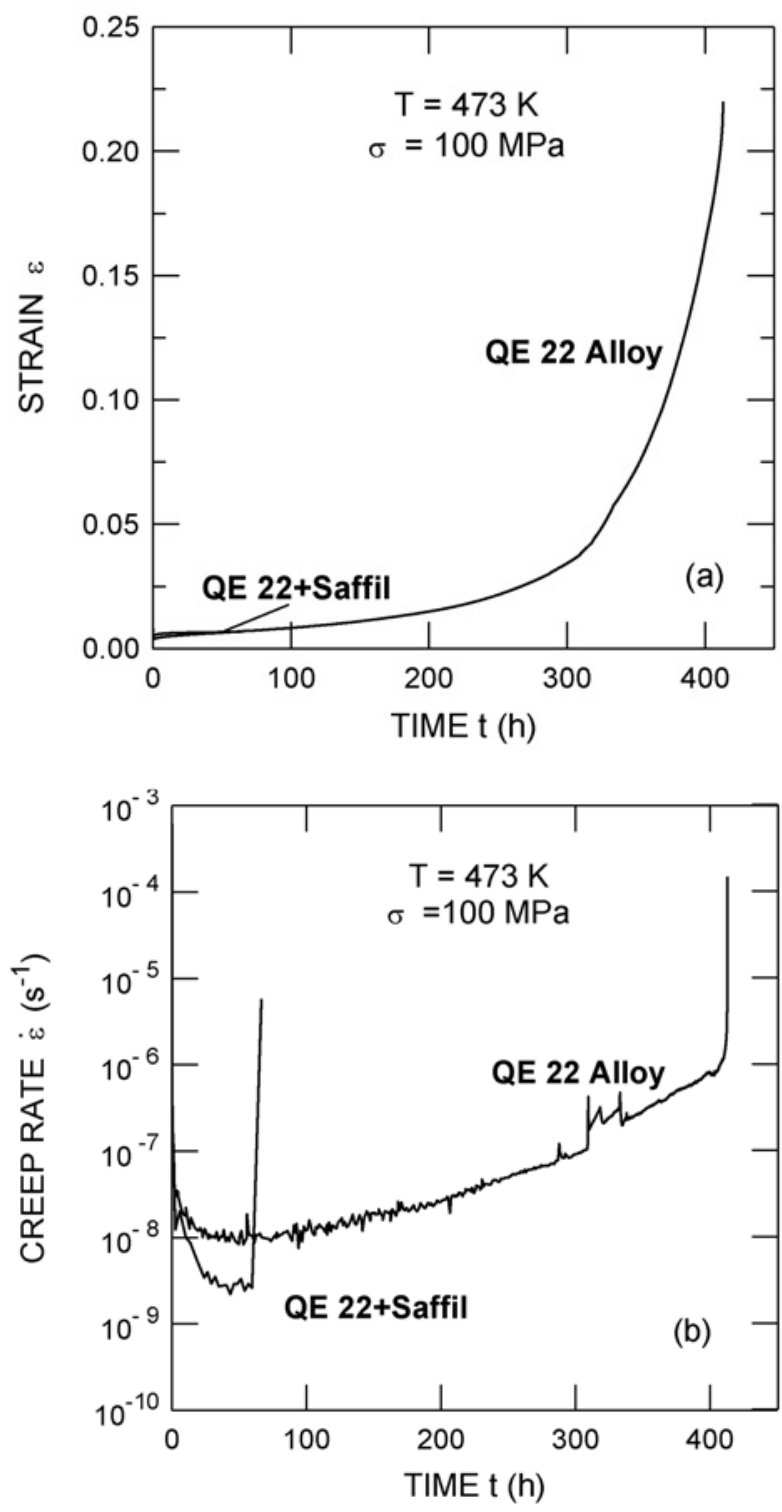

Fig. 2. Comparison of creep curves for QE22 alloy and QE22 + Saffil composite at $473 \mathrm{~K}$ and $100 \mathrm{MPa}$ : (a) standard creep curves and (b) modified creep curve.

to more generally analyse the creep behaviour of both materials, we evaluated the applied stress and temperature dependences of relevant creep parameters of both materials under investigation.

\subsection{Applied stress and temperature dependences of creep parameters}

The stress, $\sigma$, and temperature, $T$, the dependence of the minimum creep rate, $\dot{\varepsilon}_{\mathrm{m}}$, generally follow a simple Norton power-law constitutive equation [11-13]:

$$
\dot{\varepsilon}_{\mathrm{m}}=A \sigma^{n} \exp \left(-Q_{\mathrm{c}} / k T\right),
$$



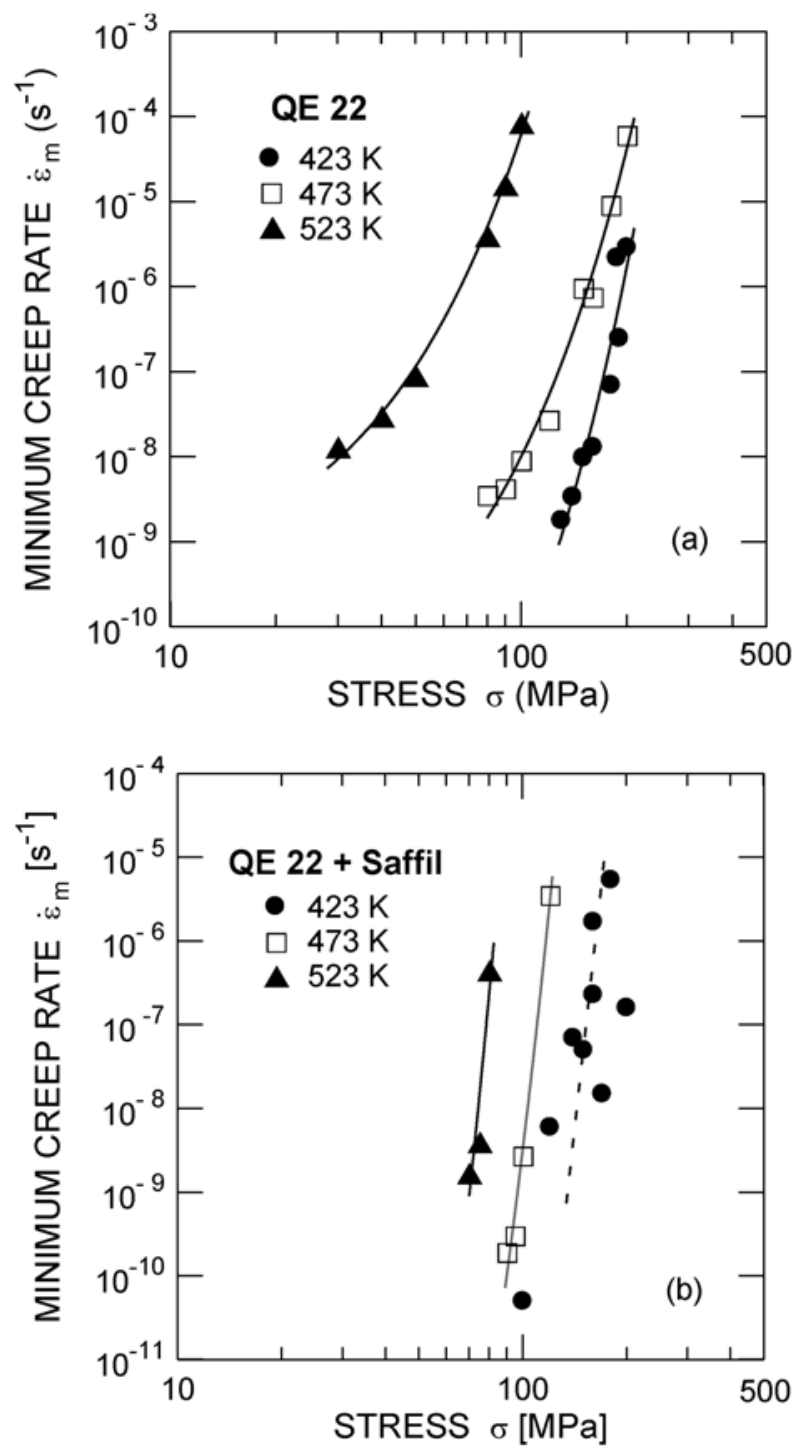

Fig. 3. Stress dependences of the minimum creep rate for (a) QE22 alloy and (b) QE22 + Saffil composite.

where $A$ is the microstructure parameter related to the material, $n=\left(\partial \ln \dot{\varepsilon}_{\mathrm{m}} / \partial \ln \sigma\right)_{\mathrm{T}}$ and is the apparent stress exponent of the minimum creep rate, $Q_{\mathrm{c}}=\left[\partial \ln \dot{\varepsilon}_{\mathrm{m}} / \partial(-1 / R T)\right]_{\sigma}$ is the activation energy for creep, $k$ is the Boltzmann constant and $T$ the absolute temperature. Summaries of the creep data for the QE22 alloy and the QE22 + Saffil composite at 423,473 , and $523 \mathrm{~K}$ are shown in Figs. 3, 4, where the minimum creep rate, $\dot{\varepsilon}_{\mathrm{m}}$, is plotted against the applied stress, $\sigma$, on a double logarithmic scale. Careful inspection of Figs. 3, 4 leads to the following observations. First, as depicted in Fig. 3, the stress dependences of the minimum creep rates for both materials have different trends, which is clearly demonstrated by the characteristic curvatures on the monolithic alloy curves $(n \neq$ const). Generally, the slopes and, there-

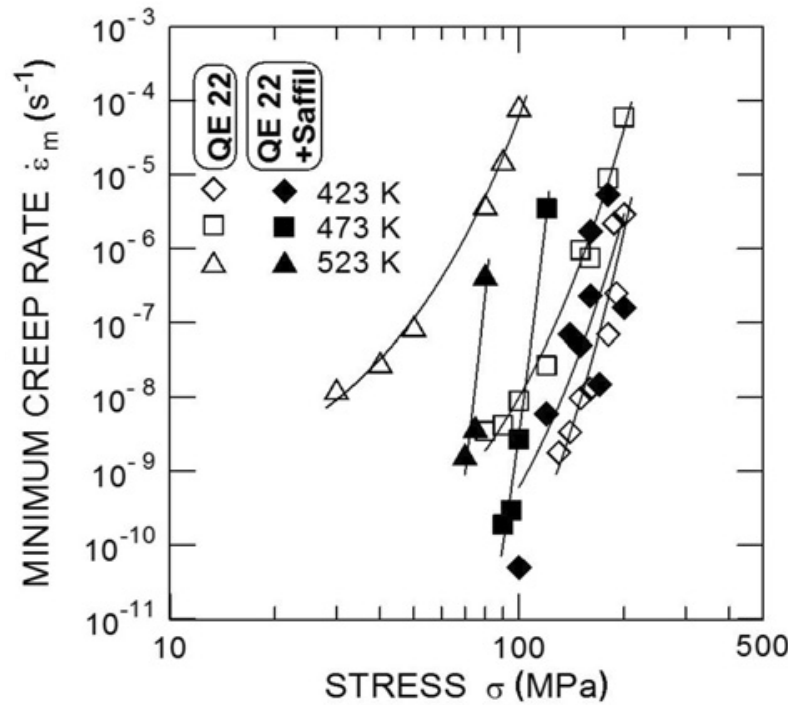

Fig. 4. Stress dependences of the minimum creep rate for QE22 alloy and QE22 + Saffil composite.

fore, the values of the apparent stress exponent, $n$, of the minimum creep rate, $\dot{\varepsilon}_{\mathrm{m}}$, of the unreinforced alloy decrease with decreasing applied stress and increasing temperature, in the range from $3.8(30 \mathrm{MPa}, 523 \mathrm{~K})$ to 20.9 (190 MPa, 423 K). In contrast, no obvious curvatures indicating such dependences can be observed in the plots for the composite under the chosen loading conditions. The very high values of $n$ for the composite are about 30-40. These anomalously high values for the stress exponent, $n$, suggest that the creep behaviour of both materials may be controlled by precipitation strengthening due to the interaction of mobile dislocations [12-16]. However, the values of $n$ for the composite are clearly higher by comparison to those for the unreinforced alloy. Such higher values of $n$ for the composite may be explained in terms of a threshold stress for creep, $\sigma_{0}[5,12]$; in this case, the creep behaviour of the composite is not driven by the total applied stress, $\sigma$, but rather by an effective stress, $\sigma_{\mathrm{e}}=\sigma-\sigma_{0}$.

Two procedures are available for estimating the magnitude of the threshold stress $\sigma_{0}$ in high temperature creep $[17,18]$. In the first procedure, the creep data are extrapolated directly from the plots of the creep rate $\dot{\varepsilon}_{\mathrm{m}}$ vs. the applied stress $\sigma$ to a lower limiting strain rate where the lines become vertical, typically at a strain order of $10^{-10} \mathrm{~s}^{-1}[18,19]$. However, there is a second simple empirical method to determine the threshold stress $\sigma_{0}$ in creep, which has been proposed by Lagneborg and Bergman [17]. If threshold stress $\sigma_{0}$ exists, Eq. (1) at selected temperature can be reduced to Eq. (3):

$$
\dot{\varepsilon}=A\left(\sigma-\sigma_{0}\right)^{n},
$$


or

$$
\dot{\varepsilon}^{1 / n}=A_{1}\left(\sigma-\sigma_{0}\right)
$$

Thus, the threshold stress, $\sigma_{0}$, can be evaluated by plotting $\dot{\varepsilon}^{1 / n}$ vs. $\sigma$ and extrapolating the $\left(\dot{\varepsilon}^{1 / n}-\sigma\right)$ curve to $\dot{\varepsilon}=0$ [17]. The intercept of this curve on the stress axis is the threshold stress, $\sigma_{0}$. In this second procedure, possible values of the stress exponent, $n$, are chosen in advance. In practice, it has been reported that both procedures give consistent values for threshold stress, $\sigma_{0}[20]$. To apply the first procedure, note that Figs. 3 and 4 do not exhibit a characteristic curvature for the true threshold stress creep behaviour. Further, Cadek and Sustek [19] proposed that it is necessary to obtain experimental data over no less than five orders of magnitude of creep rate to evaluate the appropriate values of the threshold stress. However, most experimental data from this work describe the creep behaviour of the composite only over four or less orders of magnitude of creep rate. Thus, it is difficult to establish whether the stress exponent, $n$, is genuinely constant or increasing with decreasing applied stress, indicating the threshold stress potentiality. Unfortunately, it is nearly impossible for technical reasons (unrealistic time-consuming creep tests) to perform additional creep tests at such extremely low stresses. Furthermore, the above-mentioned prerequisite of the creep rate interval can hardly be fulfilled for the investigated composite due to the occurrence of sudden fracture at creep rates lower than $10^{-9} \mathrm{~s}^{-1}$. Having only a small number of experimental points, it was appropriate to make use of the second procedure and extrapolate the data to give the threshold stress at a zero-creep strain rate [17]. Analyses were undertaken using selected values, $n=5$ and 15 for the unreinforced alloy (Fig. 5a) and $n=30$ for the composite (Fig. 5b). Detailed inspections of the individual plots in Figs. 5a,b show that, while no threshold stress was found in the case of monolithic alloy (Fig. 5a) and effective stress, $\sigma_{\mathrm{e}}$, is equivalent to the applied stress, $\sigma$, the values of the threshold stress for the composite at $473 \mathrm{~K}$ and $523 \mathrm{~K}$ were estimated as 22.2 and 18.5 MPa, respectively. However, from the disputable experimental reasons mentioned above and insufficient data, these values should be considered only very informative.

The comparison of the minimum creep rate values, $\dot{\varepsilon}_{\mathrm{m}}$, implies that the QE22 + Saffil composite exhibits an increased creep resistance compared to its monolithic alloy at low applied stresses (Fig. 4). However, this benefit decreases with increasing stress and decreasing temperature, and there is even a tendency for the reinforcement to have a deleterious effect on creep strength (Fig. 2). Further, the presence of reinforcement leads to a substantial decrease in the overall ductility of the matrix alloy. Thus, the values of strain
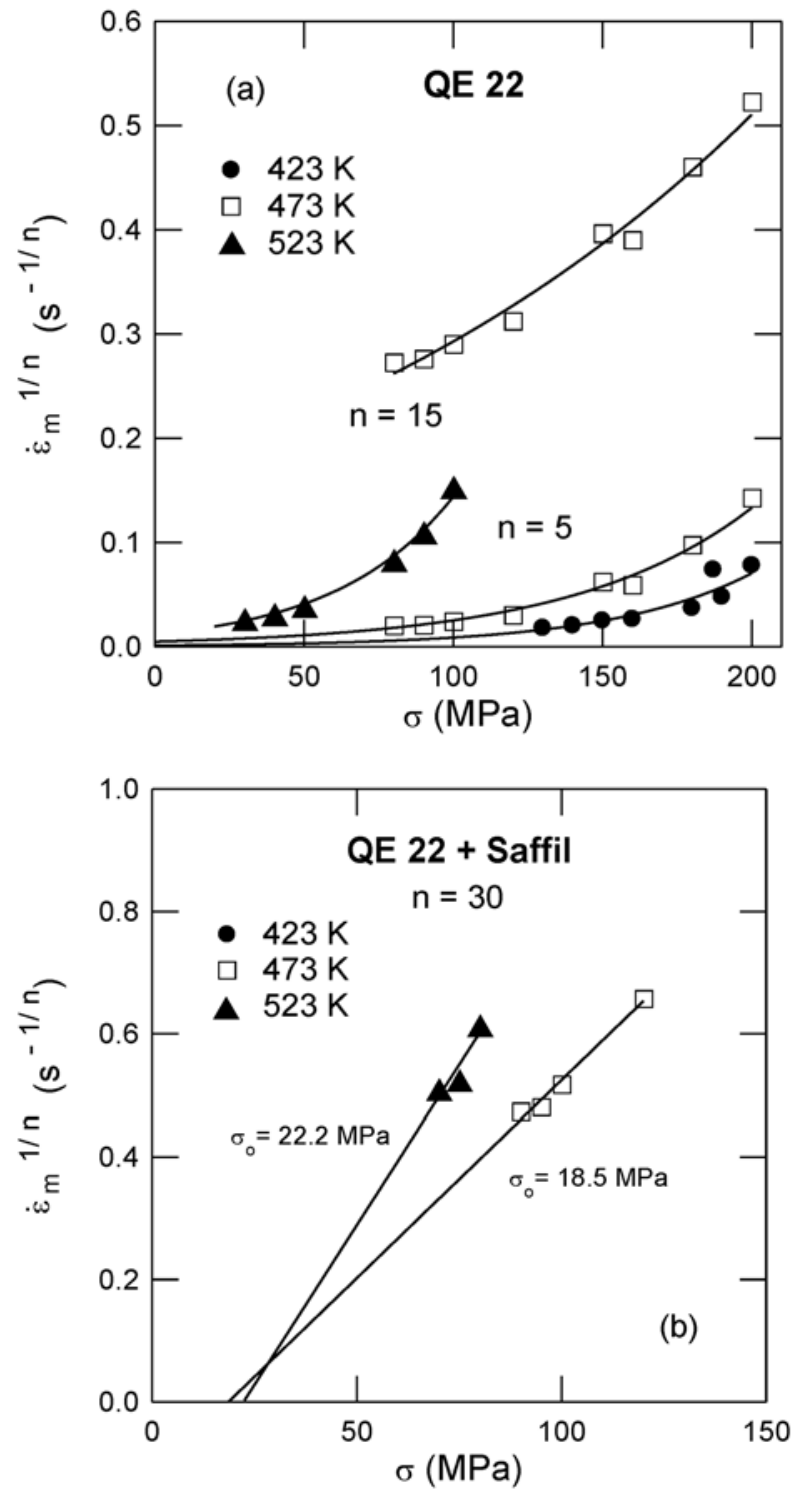

Fig. 5. Procedure for determining the threshold stress $\sigma_{0}$ at 473 and $523 \mathrm{~K}$ in: (a) QE22 alloy (using the stress exponents $n=5$ and 15), and (b) QE22 + Saffil composite (using a stress exponent $n=30$ ).

to fracture, $\varepsilon_{\mathrm{f}}$, in the composite were only $\sim 1-2 \%$ and were essentially independent of stress and temperature (Fig. 6). By contrast, strain to fracture in the monolithic alloy was markedly higher, typically up to $\sim 40 \%$. Experimentally determined times to fracture correlate with minimum creep rates (Fig. 7) through the empirical Monkman-Grant relationship [21-24]:

$$
\dot{\varepsilon}_{\mathrm{m}}=C_{0} / t_{\mathrm{f}}^{\beta}
$$

where $C_{0}$ is a parameter depending on the total strain $\varepsilon_{\mathrm{f}}$ during creep and exponent $\beta$, which can be influenced by $C_{0}$. From Fig. 7 , it is clearly seen that the Monkman-Grant relationship is linear in the studied 


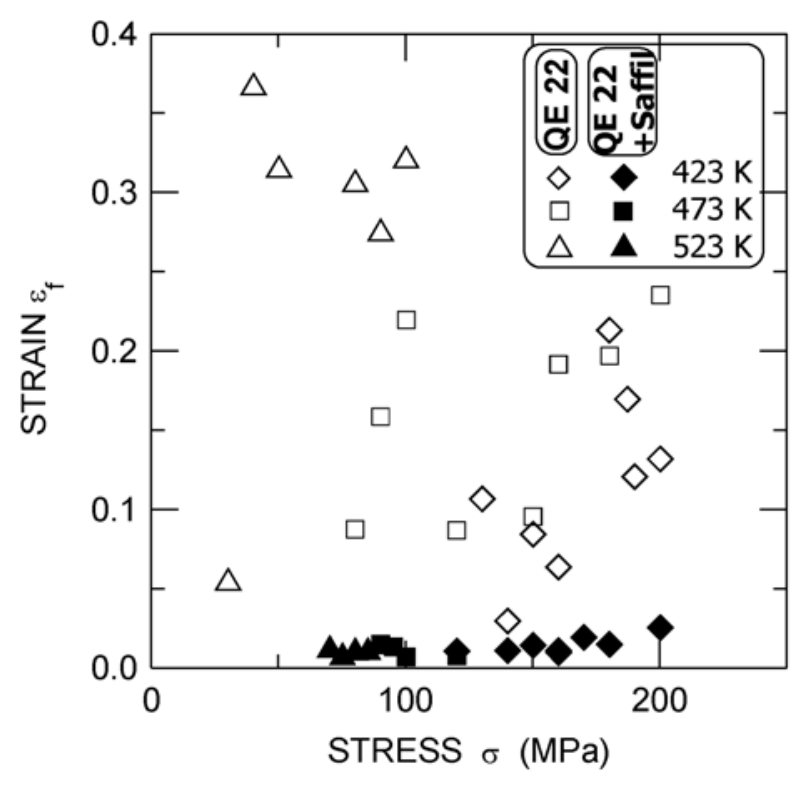

Fig. 6. Stress dependences of the creep fracture strain $\varepsilon_{\mathrm{f}}$ for QE22 alloy and QE22 + Saffil composite.

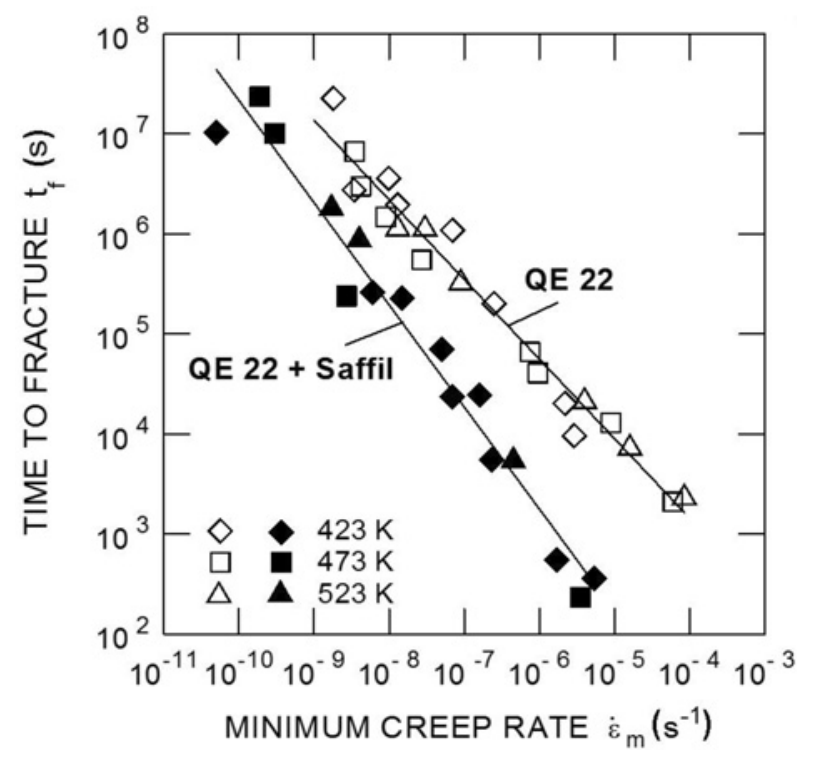

Fig. 7. Dependences of the time to fracture on the minimum creep rate (Monkman-Grant relationship [21]) for QE22 alloy and QE22 + Saffil composite.

stress range. Note, however, that $\varepsilon_{\mathrm{f}}$ itself could be strongly influenced by the mechanisms of the fracture process, which could explain a shift of the composite dependence towards shorter times to fracture at the same minimum creep rates (Fig. 7).

In a similar way as in Eq. (1), the constitutive equation for the time to fracture, $t_{\mathrm{f}}$, in its functional form gives [25]:
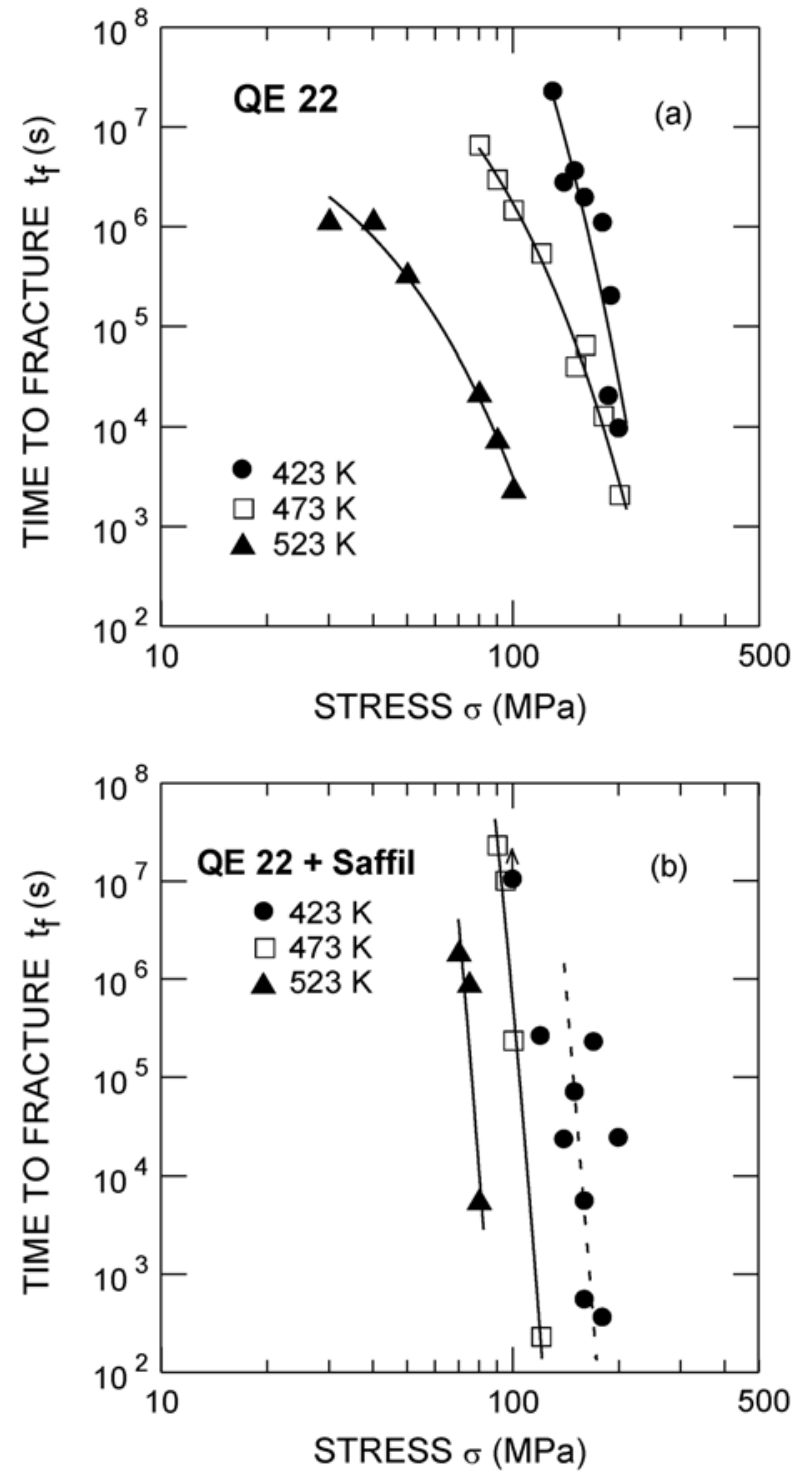

Fig. 8. Stress dependences of the time to fracture for: (a) QE22 alloy and (b) QE22 + Saffil composite.

$$
t_{\mathrm{f}}=B(\sigma)^{-m} \exp \left(Q_{\mathrm{f}} / R T\right)
$$

where $B$ is a material constant, $m=-\left(\partial \ln t_{\mathrm{f}} / \partial \ln \sigma\right)$ is the stress exponent of the time to fracture, $t_{\mathrm{f}}$, and $Q_{\mathrm{f}}$ is the activation energy for fracture life.

The double logarithmic plots of the time to fracture, $t_{\mathrm{f}}$, as a function of applied stress for both materials, are shown in Figs. 8 and 9. The experimentally determined values of the apparent stress exponent of the time to fracture, $m$, of both the composite and the alloy are similar to the relevant values of $n$, which, together with a valid M-G relationship, imply the close link between creep deformation and fracture processes. The difference in the lifetimes of the reinforced and unreinforced material mainly depends on the creep loading conditions, the course of the tertiary 


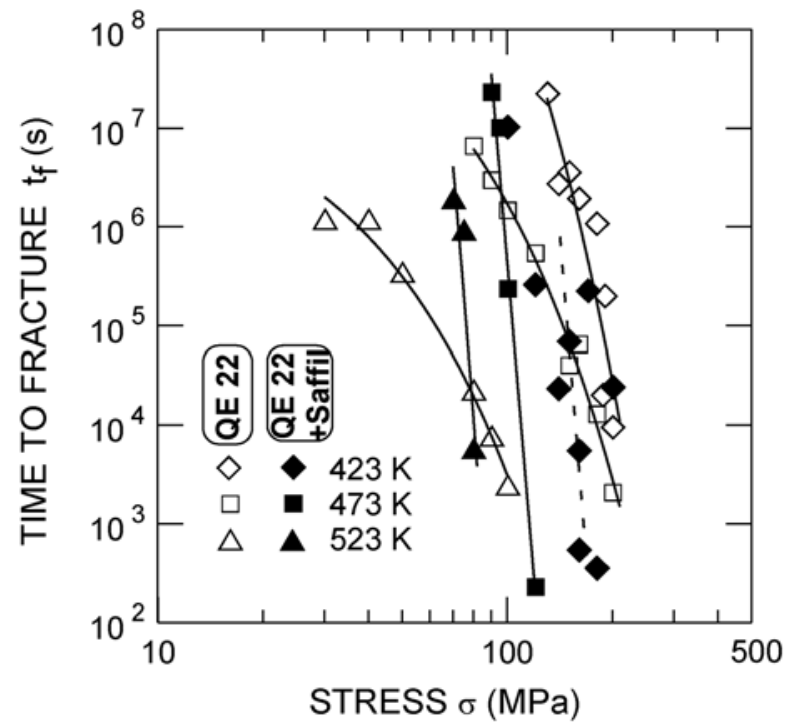

Fig. 9. Stress dependences of the time to fracture for QE22 alloy and QE22 + Saffil composite.

creep stage, final fracture mode, and fracture strain, $\varepsilon_{\mathrm{f}}$.

\subsection{Microstructural observations}

Detailed microstructural investigations of the squeeze-cast QE22 monolithic alloy and the QE 22-20 vol. $\% \mathrm{Al}_{2} \mathrm{O}_{3}$ (f) composite were reported by Kiehn et al. [26]. Therefore, special attention was given in this work to a study of the microstructural changes arising from creep exposure in the monolithic QE22 alloy and the QE22 + Saffil composite. In the composite, the fibres can act as nucleation centres in the precipitation process, promoting precipitation of $\mathrm{Al}_{2} \mathrm{Nd}$, $\mathrm{Mg}(\mathrm{Ag})_{12} \mathrm{Nd}$, and $\mathrm{Mg}_{3} \mathrm{Ag}$ phases; their morphologies can be seen in Fig. 10a for the composite in the state before creep. However, the concentration of the precipitates at the fibre/matrix was very small. During creep exposure, the number of $\mathrm{Mg}(\mathrm{Ag})_{12} \mathrm{Nd}$ particles at the fibres grew slightly (Fig. 10b) and changed their composition; the $\mathrm{Nd} / \mathrm{Ag}$ ratio (in at.\%) of the initial state, $\approx 0.8$, changed to close to 0.5 for the crept specimen (473 K, $90 \mathrm{MPa}$, and 6512 hours).

The $\mathrm{Al}$ content in the matrix was enhanced due to the decomposition of an alumina preform binder. The evolution of the particle population inside the grains leads to the formation of $\mathrm{Al}_{2} \mathrm{Nd}$-like cubic particles in creep at $423 \mathrm{~K}$. At temperatures above $423 \mathrm{~K}$, these particles are replaced by hexagonal $\beta$-phase or tetragonal $\mathrm{Mg}(\mathrm{Ag})_{12} \mathrm{Nd}$ precipitates, which often nucleate on dislocations, as shown in Fig. 10c. The precipitation process in the grain interiors of the unreinforced alloys is different and involves only a change of the morphological features of the tetragonal semi-coherent
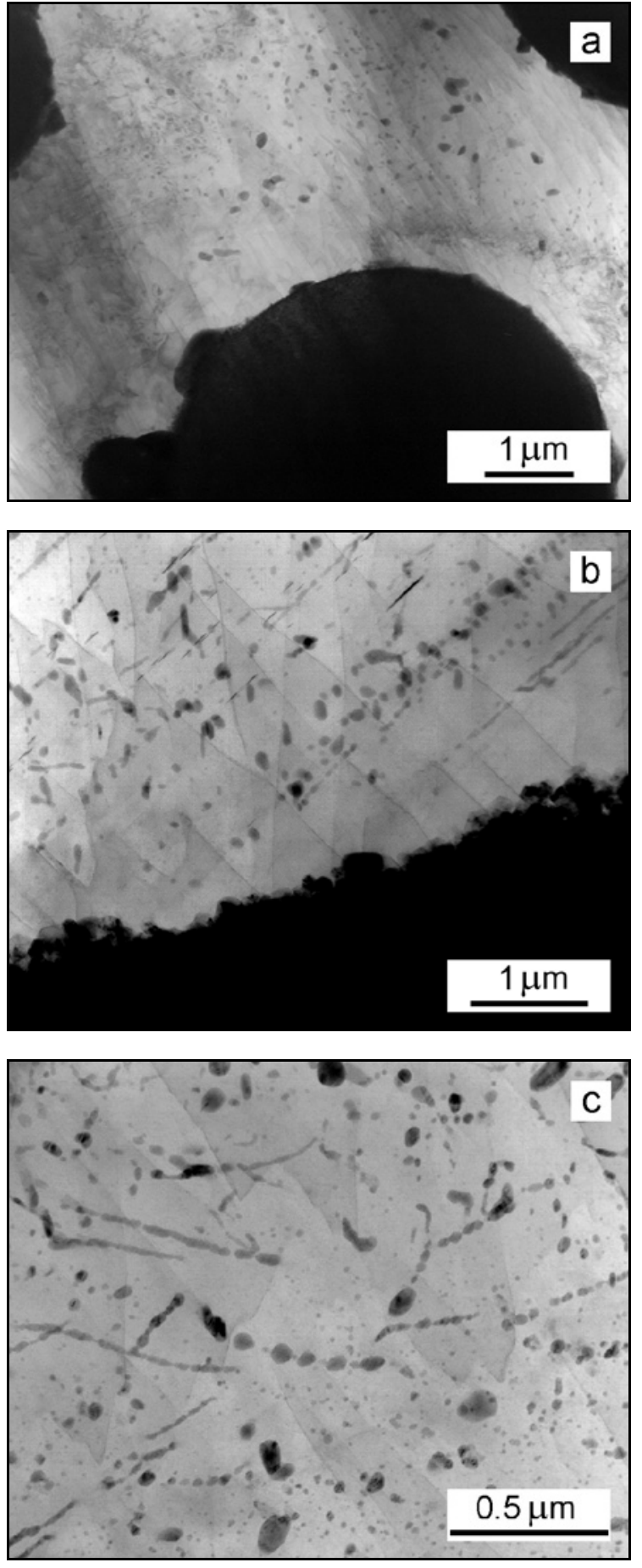

Fig. 10. TEM micrographs of QE22 + Saffil composite: (a) before creep exposure and (b), (c) after creep at $473 \mathrm{~K}$, $90 \mathrm{MPa}$ for $t_{\mathrm{f}}=6512 \mathrm{~h}$ showing precipitates at fibre surface and a detail view of intragranular precipitates.

$\mathrm{Mg}_{12} \mathrm{Nd}$ particles existing in the alloy after the $\mathrm{T} 6$ heat treatment. It should be noted that the formation of second-phase particles along the fibre-matrix interface reduces the concentration of alloying elements in the matrix so that there is a consequent decrease in 
the density of obstacles opposing dislocation motion. The formation of Guinier-Preston zones between 423 and $523 \mathrm{~K}$ was not observed but cannot be fully excluded due to complicated changes overlapping in the population of various $\mathrm{Mg}_{12} \mathrm{Nd}$-based precipitates.

\subsection{Fractography and load transfer}

Creep behaviour and creep resistance in metal matrix composites may be substantially influenced by the development of creep damage and fracture processes [27, 28]. Based on the experimental results on a short fibre reinforced aluminium alloy, Dlouhý et al. reported [29-31] that, in the case of good bonding between the $\mathrm{Al}_{2} \mathrm{O}_{3}$ Saffil short fibres and matrix and under conditions of power-law creep in the matrix, the formation of work-hardened zones (WHZ) occurred. Due to the WHZ at the matrix/fibre interface, the fibres were broken as a result of overloading. However, such behaviour was not frequently observed in the present investigated magnesium short fibre QE 22 composite. Very few fibres were broken outside the final creep fracture, but this may have occurred while manufacturing metal matrix composite by squeeze casting. A fractographic investigation failed to reveal substantial fibre cracking and breakage on the longitudinal metallographic sections along the gauge length of the crept specimens. The reason that the fibres were not broken may be the small creep strain under load (only 1-2\%) and/or missing the work hardening zone. More intensive fibre breakage was restricted only to the creep fracture surface and/or the region very near the fracture path, suggesting that creep fracture occurs by the propagation of the main crack during the final stage of the creep fracture process (Fig. 11).

However, an intensive debonding of the matrix/fibre interfaces was revealed at the creep fracture surfaces of the QE + Saffil composite at high stresses (Fig. 12). Furthermore, detailed investigations of the fracture surfaces proved that a considerable amount of the fibres were pulled out (Fig. 13). Generally, the extent of interfacial debonding was markedly increasing with decreasing creep testing temperature and increasing applied tensile stress. The final brittle creep fracture in the composite occurs by relatively fast propagation of the main crack along individual aggregates of fibre damage (Fig. 14a). In this case, the inherent creep ductility of the matrix was not exhausted due to premature fracture caused by reaching the ultimate state of creep damage [32]. In contrast, the final intergranular creep fracture of the QE 22 alloy was caused by a local strain-induced instability of the dislocation microstructure leading to a loss of an external section of the creep specimen. A mixed-mode of transgranular/intergranular fracture was observed on fractured creep specimens, Fig. 14b.
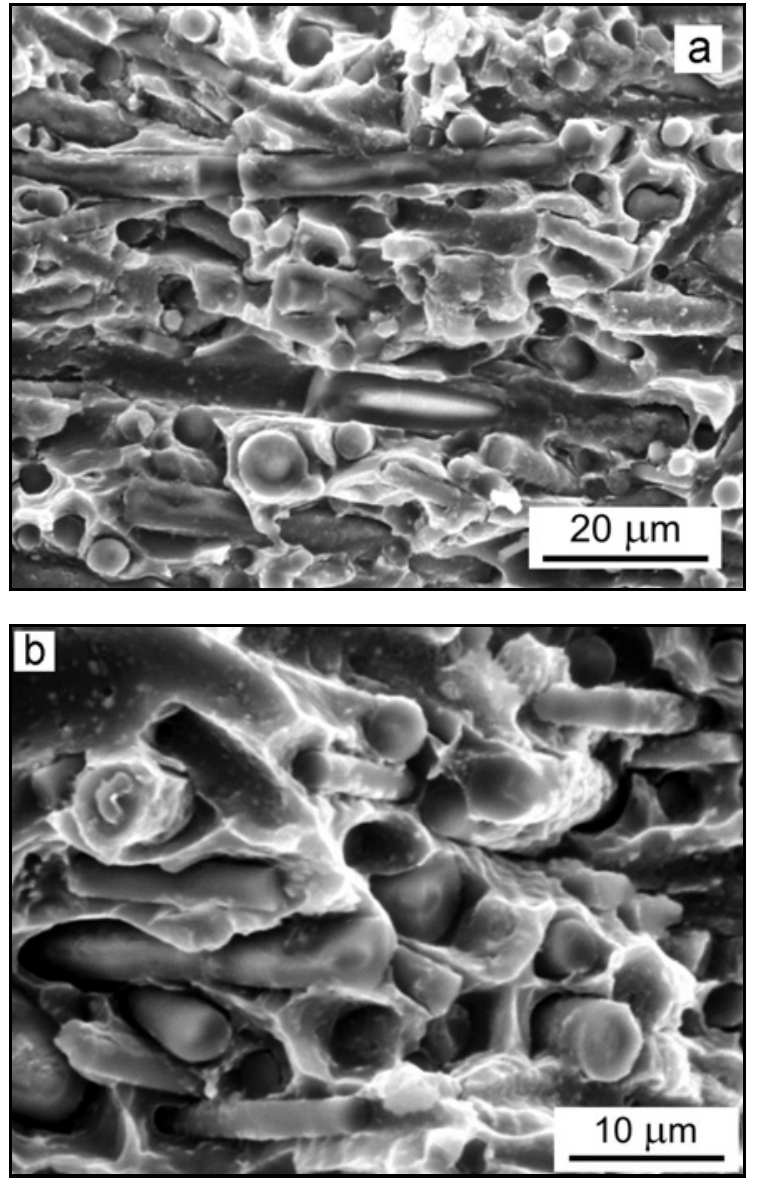

Fig. 11. SEM micrographs of QE22 + Saffil composite showing (a) fibre breakage at the creep fracture surface and (b) a detail (creep at $473 \mathrm{~K}$ and $120 \mathrm{MPa}$ for $t_{\mathrm{f}}=$ $0.07 \mathrm{~h})$.

In general, creep strengthening of the magnesium composites may occur by either direct or indirect mechanisms. Direct strengthening is due to a load transfer from the matrix to the reinforcements. Thus, load transfer is accompanied by a redistribution of stresses in the matrix, and this reduces the effective stress for creep. Indirect strengthening may be caused by the microstructural changes in the matrix of the composite, which retard and/or inhibit dislocation motion and lead to threshold stress for the creep that increases the creep resistance. The QE22 + Saffil composite exhibits good creep resistance compared to its monolithic alloy at low stresses; however, this benefit decreases considerably with increasing stress. Such behaviour may be explained by a load transfer in the composite. The occurrence of load transfer during the creep of mostly aluminium composites has been reported $[8,33-38]$. It should be stressed that composite mechanics is a highly complex issue [39-41]. Nevertheless, in the presence of load transfer, it is possible to describe its effect on creep by introducing the load 

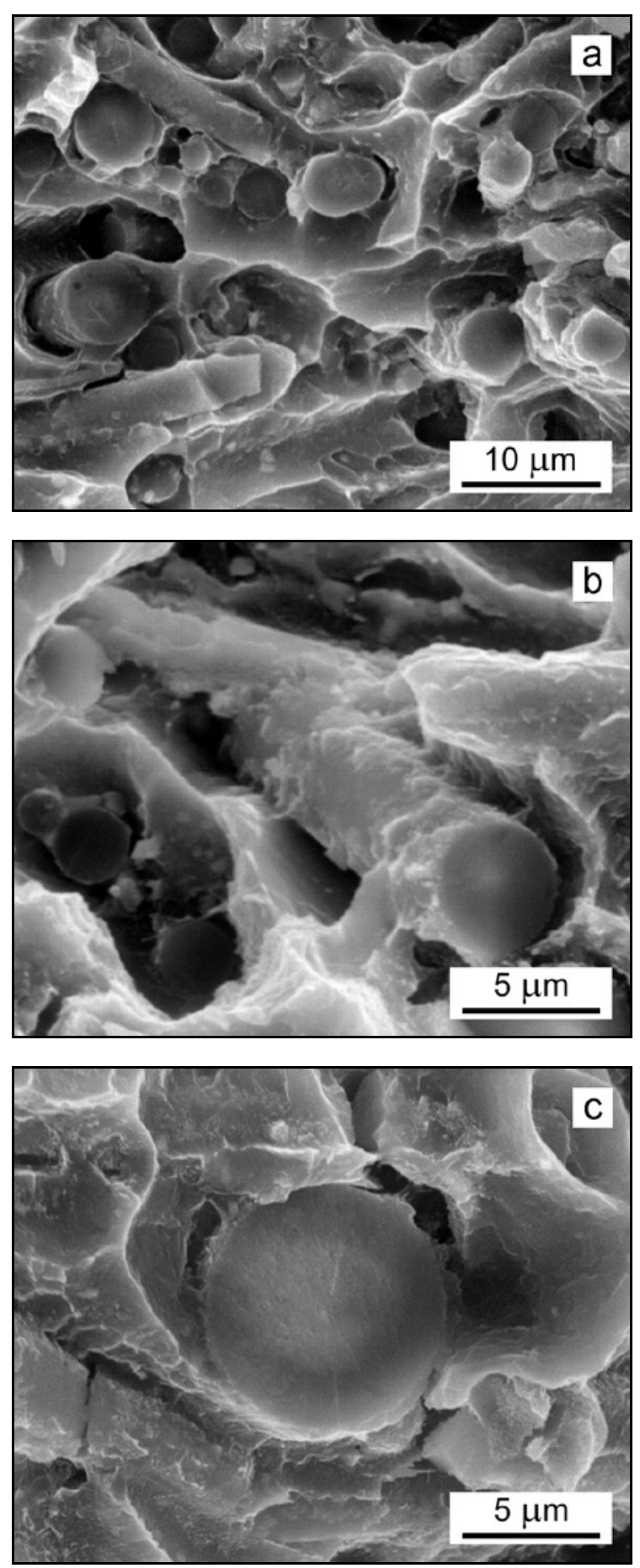

Fig. 12. SEM micrographs of QE22 + Saffil composite showing (a) an intensive debonding of the matrix/fibre interfaces and (b), (c) details (creep at $423 \mathrm{~K}$ and $100 \mathrm{MPa}$ for $\left.t_{\mathrm{f}}=2887 \mathrm{~h}\right)$.

transfer coefficient, $\alpha$, which characterizes the bearing and load transfer of short fibre. Using a simple empirical method [8, 41, 42], the minimum creep rate of the composite can be expressed as:
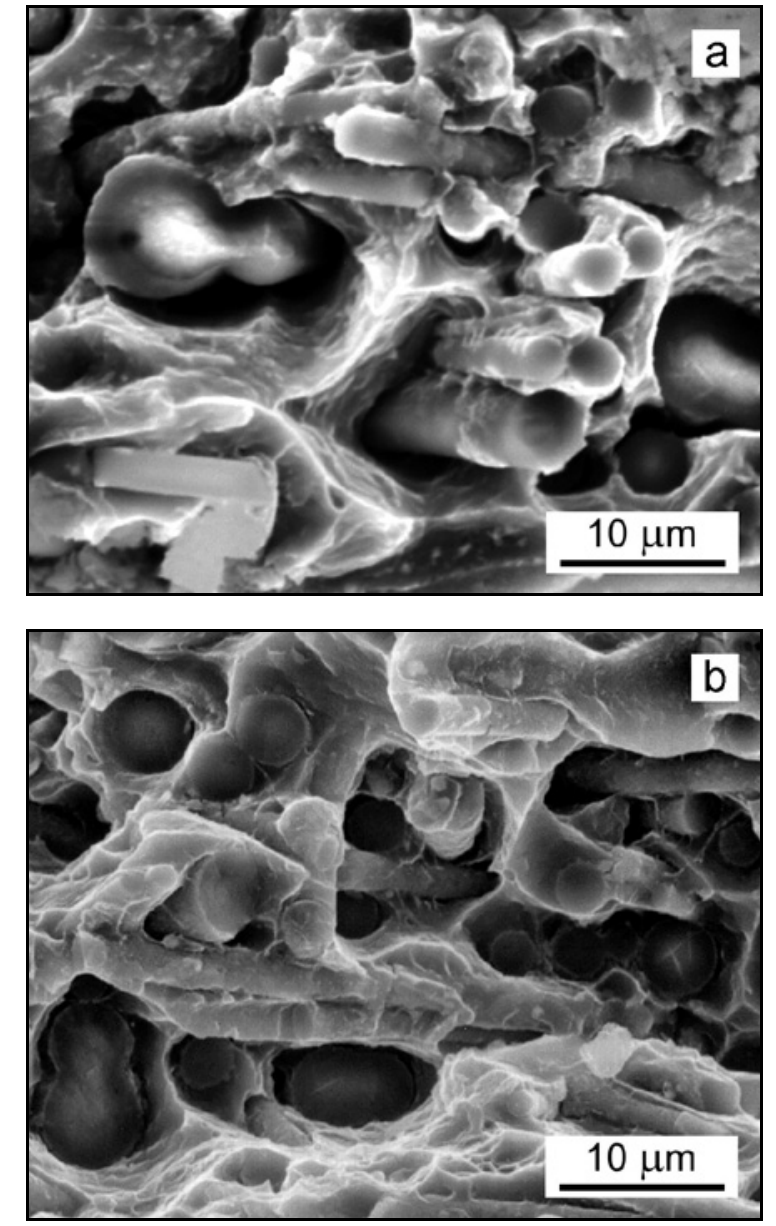

Fig. 13. SEM micrographs of QE22 + Saffil composite showing the pull-out of fibres at creep fracture surfaces: (a) creep at $473 \mathrm{~K}, 120 \mathrm{MPa}$ for $t_{\mathrm{f}}=0.07 \mathrm{~h}$, (b) creep at $523 \mathrm{~K}, 75 \mathrm{MPa}$ for $t_{\mathrm{f}}=264 \mathrm{~h}$.

$$
\dot{\varepsilon}_{\mathrm{c}} / \dot{\varepsilon}_{\mathrm{m}}=(1-\alpha)^{n}
$$

where $\dot{\varepsilon}_{\mathrm{c}}$ is the minimum creep rate of the composite, $\dot{\varepsilon}_{\mathrm{m}}$ is the minimum creep rate of the alloy, and $n$ is the stress exponent under the same loading conditions. It is assumed that the values of load transfer coefficient, $\alpha$, lie within the range from 0 (no-load transfer) to 1 (full-load transfer) [8, 41, 42]. Unfortunately, the values of the load transfer coefficient $\alpha$ for the QE22 composite cannot be rigorously obtained due to insufficient creep data inferred from this study. Despite this fact, an illustrative estimation can serve for the values of $\alpha$ inferred from the data in Fig. 3 for which the rate $\dot{\varepsilon}_{\mathrm{c}}<\dot{\varepsilon}_{\mathrm{m}}$. The experimentally estimated values of $\alpha$ were found to be 0.11 and 0.26 for 423 and $523 \mathrm{~K}$, respectively. Thus, these small values of $\alpha$ imply a weak bond between the matrix alloy and the reinforcing fibres. In comparison, it is interesting to notice that the creep characteristics of an AZ91 magnesium alloy (Mg, 9 wt.\% Al, 1 wt.\% $\mathrm{Zn}$ ) reinforced with 20 

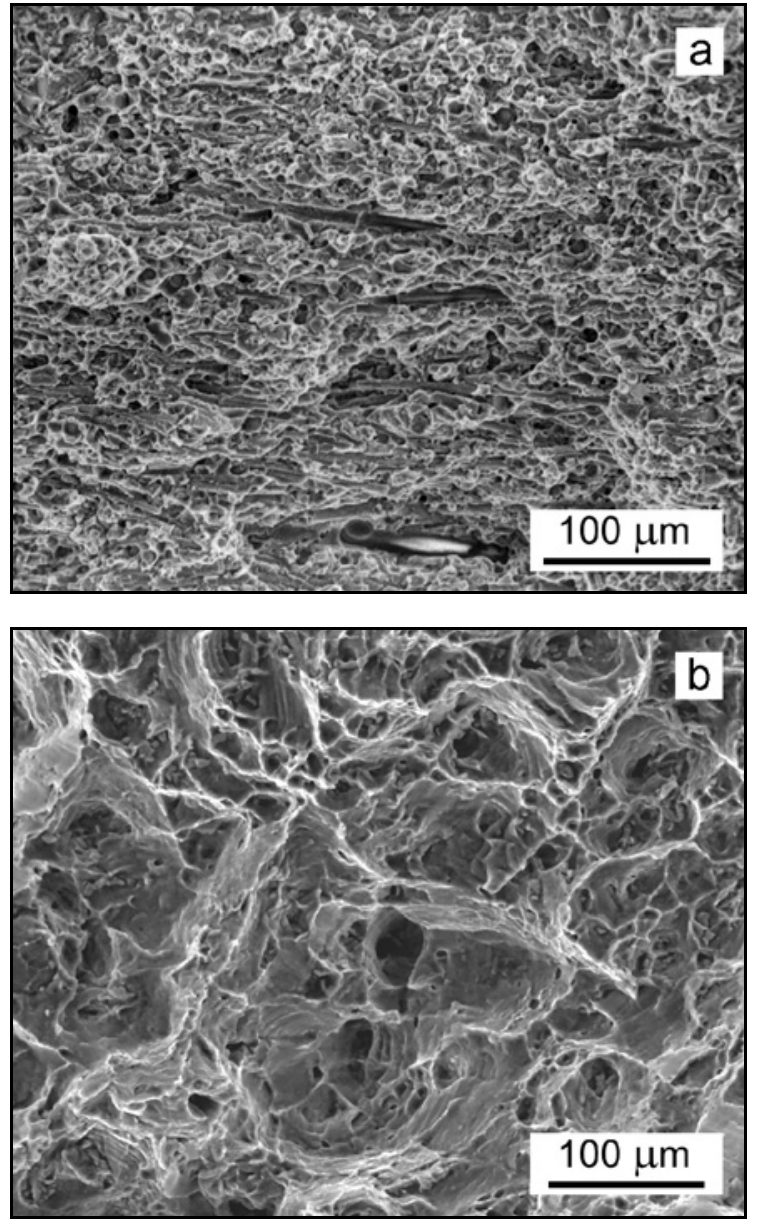

Fig. 14. SEM micrographs of creep fracture surface: (a) QE22 + Saffil composite (creep at $523 \mathrm{~K}, 75 \mathrm{MPa}$ and $t_{\mathrm{f}}=$ $264 \mathrm{~h}$ ) and (b) QE22 alloy (creep at $523 \mathrm{~K}, 50 \mathrm{MPa}$ and $\left.t_{\mathrm{f}}=98 \mathrm{~h}\right)$.

vol.\% $\mathrm{Al}_{2} \mathrm{O}_{3}$ short fibres (Saffil) showed that the creep resistance of the reinforced alloy was considerably improved compared to the unreinforced matrix alloy over the entire range of creep rate measured [8]. The determined values of $\alpha$ were within the 0.79 to 0.90 range. It should be noted that the AZ91 magnesium alloy is less creep-resistant than the high-strength QE22 alloy $[3,5-7]$. Thus, the results indicate the dominant importance of the choice of the composite matrix alloy and the reinforcement used in composite design.

Observed differences in the minimum creep rates and the lifetimes of the composite and unreinforced QE22 alloy (Figs. 3, 4, 8, and 9) imply a critical weakening of the fibre/matrix interface at high stresses. The substantial increase of acting stress is caused by the loss of a loading section of the creep specimen due to debonding at the fibre/matrix interface. With extreme values of the stress exponent, $n$, of the composite creep rate, this should lead to a considerable increase of the creep rate (Eq. (1)). Thus, Figs. 3 and
4 reveal that independent of the testing temperature, at high stresses, the minimum creep rate of the composite becomes essentially equal or even higher to that of the unreinforced matrix alloy. As a result, the composite creep strength approaches that of the matrix alloy at intermediate creep rates and falls below it at high strain rates. Following the results of fractographic observations, an extensive debonding occurs at $423 \mathrm{~K}$ (Fig. 12), while a less limited interfacial debonding was revealed at $523 \mathrm{~K}$. Thus, it can be expected that no direct effective strengthening due to load transfer from matrix to the fibres occurs at $423 \mathrm{~K}$. In fact, in the limit of zero interface strength, where no stress can be transmitted to the fibres, the composite may be weaker than the matrix alone. These results suggest that direct composite strengthening controls the creep behaviour of the short fibre QE22 composite. Indirect composite strengthening may be caused by an additional temperature-dependent precipitation process in the composite due to the presence of the reinforcement, which leads to an attractive interaction between dislocations and incoherent second-phase particles. This mechanism could dominate in low-stress regions.

\section{Conclusions}

A comparison between the creep characteristics of the high-strength creep-resistant QE22 alloy reinforced with $20 \mathrm{vol} . \% \mathrm{Al}_{2} \mathrm{O}_{3}$ (Saffil) short fibres and unreinforced QE22 matrix alloy under comparable experimental loading conditions implies that creep strengthening in the composite arises mainly from effective load transfer from matrix to fibres, provided that no extensive debonding of the fibre/matrix interfaces and substantial breakage of fibres during creep exposure occur. The creep behaviour and the creep resistance of the composite may be substantially influenced by the creep loading conditions, especially by the level of applied stress. The creep resistance of the composite was improved in comparison to the unreinforced alloy in low-stress regions. Furthermore, the beneficial effect of the reinforcement on the creep rate and, thus, improvement of the creep resistance was better with increasing testing temperature. In contrast, the creep resistance of the composite decreases with increasing applied stress, and there is a tendency for the reinforcement to have no significant or even negative effect on creep resistance at the highest experimental stresses.

\section{Acknowledgements}

The IPMinfra research infrastructure supported by the Ministry of Education, Youth and Sports of the Czech 
Republic through project No. LM2015069 was used. The authors wish to thank Professor Karl Ulrich Kainer of Helmholz-Zentrum Geesthacht - Zentrum für Material und Küstenforschung GmbH, Geesthacht, Germany, for his kind support in supplying the experimental materials and for several helpful discussions.

\section{References}

[1] W. Blum, B. Watzinger, P. Weidinger, Creep Resistance of Mg-base Alloys, in: B. Mordike, K.U. Kainer (Eds.), Magnesium Alloys and their Applications, MATINFO Werkstoff-Informationsgesellschaft mbH, Frankfurt, 1998, pp. 49-60. ISBN 3-88355-255-0.

[2] K. U. Kainer, Cast Magnesium Alloys Reinforced by Short Fibres, in: B. L. Mordike, F. Hehmann (Eds.) Magnesium Alloys and their Applications, DGM, Oberursel, 1992, pp. 415-422. ISBN 978-3883551845.

[3] B. L. Mordike, K. U. Kainer, F. Moll, B. Sommer, Creep Behavior of Magnesium Matrix Composites, in: E. Aghion, D. Eliezer (Eds.), Proc. $1^{\text {st }}$ Israeli Int. Conference on Magnesium Science \& Technology, MAGNESIUM 97, Magnesium Research Institute (MRI) Ltd., Beer-Sheva, 1998, pp. 178-184.

[4] P. Lukac, Z. Trojanova, Z. Drozd, Mechanical and Physical Properties of AZ91 Alloy and Composite, in: E. Aghion, D. Eliezer (Eds.), Proc. $2^{\text {nd }}$ Israeli Int. Conference on Magnesium Science \& Technology, MAGNESIUM 2000, Magnesium Research Institute (MRI) Ltd., Beer-Sheva, 1998, pp. 308-320.

[5] F. Moll, F. Chmelík, P. Lukáč, B. L. Mordike, K. U. Kainer, Creep behaviour of a QE22-SiC particle reinforced composite investigated by acoustic emission and scanning electron microscopy, Mater. Sci. Eng. A 291 (2000) 246-249. doi:10.1016/S0921-5093(00)00963-1

[6] V. Sklenicka, M. Pahutova, K. Kucharova, M. Svoboda, T. G. Langdon, Creep processes in magnesium alloys and their composites, Metall. Mater. Trans. A 33 (2002) 883-889. doi:10.1007/1-4020-2112-7-21

[7] Z. Trojanová, V. Gärtnerová, P. Lukáč, Z. Drozd, Mechanical properties of $\mathrm{Mg}$ alloys composites with short Saffil ${ }^{\circledR}$ fibres, J. Alloys Compd. 378 (2004) 19-26. doi:10:1016/j.allcom.2003.12.047

[8] V. Sklenička, K. Kuchařová, M. Kvapilová, M. Svoboda, Factors influencing creep resistance in discontinuously reinforced magnesium metal matrix components, Kovove Mater. 53 (2015) 221-229. doi:10.4149/km_2015_4_221

[9] A. Dey, K. M. Pandey, Magnesium metal matrix composites - A review, Reviews on Advanced Materials Science 42 (2015) 58-67. http://www.ipme.ru/e-journals/RAMS/no_14215/ 07_14215_dey.pdf

[10] T. Hostinský, J. Cadek, A constant tensile stress creep testing machine, J. Test. Eval. 4 (1976) 26-28. doi:10.1520/JTE10503J

[11] A. K. Mukherjee, J. E. Bird, J. E. Dorn, Experimental correlations for high-temperature creep, ASM Trans. Quart. 62 (1969) 155-179.

[12] J. Čadek, Creep in Metallic Materials, Elsevier Science Publishers, Amsterdam, 1988.
[13] M. E. Kassner, Fundamentals of Creep in Metals and Alloys, Second Edition, Elsevier Ltd., Amsterdam, 2009 .

[14] C. J. Bettles, M. A. Gibson, Microstructural Design for Enhanced Elevated Temperature Properties in Sand- castable Magnesium Alloys, in: K. U. Kainer (Ed.), Magnesium, Proc. $6^{\text {th }}$ Int. Conference Magnesium Alloys and Their Applications, Wiley-VCH Verlag GmbH \& Co., Weinheim, 2004, pp. 1-11. ISBN 3-527-30975-6.

[15] O. A. Lambri, W. Riehemann, Damping due to incoherent precipitates in commercial QE22 magnesium alloy, Scripta Mater. 52 (2005) 93-97. doi:10.1016/i.scriptamat.2004.09.021

[16] O. A. Lambri, G. J. Cuello, W. Riehemann, J. Lucioni, On the precipitation processes in commercial QE22 magnesium alloy, Z. Metallkde 98 (2007) 501505. doi:10.3139/146.101493

[17] R. Lagneborg, B. Bergman, The stress/creep rate behaviour of precipitation-hardened alloys, Metal. Sci. 10 (1976) 20-28. doi:10.1179/030634576790431462

[18] Y. Li, T. G. Langdon, A simple procedure for estimating threshold stress in the creep of metal matrix composites, Scripta Mater. 36 (1997) 1457-1460. doi:10.1016/S1359-6462(97)00041-9

[19] J. Cadek, V. Sustek, Comment on "steady state creep behaviour of silicon carbide reinforced aluminium composites", Scripta Metall. Mater. 30 (1994) 277282. doi:10.1016/0956-716X(94)90374-3

[20] Y. Li, T. G. Langdon, An examination of creep data for an Al-Mg composite, Metall. Mater. Trans. A 28 (1997) 1271-1273. doi:10.1007/s11661-997-0293-1

[21] F. C. Monkman, N. J. Grant, An empirical relationship between rupture life and minimum creep rate in creep-rupture test, Proc. ASTM 56 (1956) 593-620.

[22] F. Dobeš, K. Milička, The relation between minimum creep rate and time to fracture, Met. Sci. 10 (1976) 382-384. doi:10.1080/03063453.1976.11683560

[23] V. Sklenička, K. Kuchařová, P. Král, M. Kvapilová, J. Dvořák, Applicability of empirical formulas and fractography assessment of creep life and creep fracture modes of tempered martensitic steel, Kovove Mater. 55 (2017) 69-80. doi:10.4149/km_2017_2_69

[24] K. Maruyama, N. Seiko, K. Yoshimi, Changes in Monkman-Grant relation among four creep regions of modified 9Cr-1Mo steel, Mater. Sci. Eng. A 749 (2019) 223-234. doi:10.1016/jmsea.2019.02.003

[25] K. Maruyama, Fracture mechanism map and fundamental aspects of creep fracture, in: F. Abe, T.-U. Kern, R. Viswanathan (Eds.), Creep-resistant steels, Woodhead Publishing Ltd., Abington, 2008, pp. 350364. ISBN 978-1-84569-178-3.

[26] J. Kiehn, B. Smola, P. Vostry, I. Stulikova, K. U. Kainer, Microstructure changes in isochronally annealed alumina fibre reinforced $\mathrm{Mg}-\mathrm{Ag}-\mathrm{Nd}-\mathrm{Zr}$ alloy, Phys. Status Solidi (a) 164 (1997) 709-723. doi:10.1002/1521-396X(199712)164:2\%3C709::AIDPSSA709\%3E3.0.CO;2-B

[27] S. T. Mileiko, Metal and Ceramic Composites, Elsevier Science B.V., Amsterdam, 1997. ISBN 0-444-82814-1.

[28] G. Eggeler, On the mechanism of creep in short fibre reinforced aluminium alloys, Z. Metallkd. 85 (1994) $39-46$. 
[29] A. Dlouhý, G. Eggeler, N. Merk, A micromechanical model for creep in short fibre reinforced aluminium alloys, Acta Metall. Mater. 43 (1995) 535-550. doi:10.1016/0956-7151(94)00255-G

[30] A. Dlouhý, N. Merk, G. Eggeler, B. Ilschner, in: B. Wilshire, R. W. Evans (Eds.), Creep in Engineering Materials and Structures, The Institute of Materials, London, 1993, pp. 361-370.

[31] A. Dlouhý, G. Eggeler, Modelling of high temperature deformation in MMCs, in: C. Moura Branco, R. Ritchie, V. Sklenička (Eds.), Mechanical Behaviour of Materials at High Temperature, Kluwer Academic Publishers, Dordrecht, 1996, pp. 515-534. ISBN 07923-4113-9.

[32] V. Sklenicka, High temperature intergranular damage and fracture, Mater. Sci. Eng. A 234 (1997) 30-36. doi:10.1016/S0921-5093(97)00172-X

[33] A. Kelly, K. N. Street, Creep of discontinuous fibre composites, I. Experimental behaviour of leadphosphor bronze. Proc. Roy. Soc. A 328 (1972) 267282. doi:10.1098/rspa.1972.0077

[34] A. Kelly, K. N. Street, Creep of discontinuous fibre composites, II. Theory for the steady-state, Proc. Roy. Soc. A 328 (1972) 293-293. doi:10.1098/rspa.1972.0078

[35] A. B. Pandey, S. S. Mishra, Y. R. Mahajan, Steady state creep behavior of silicon carbide particulate reinforced aluminum composite, Acta Metal. Mater. 40 (1992) 2045-2052. doi:10.1016/0956-7151(92)90190-P
[36] K. T. Park, F. A. Mohamed, Creep strengthening in a discontinuous $\mathrm{SiC}-\mathrm{Al}$ composite, Metall. Mater. Trans. A 26 (1995) 3119-3129. doi:10.1007/BF02669441

[37] Y. Li, T. G. Langdon, Creep behavior of a reinforced Al-7005 alloy: implications for the creep processes in metal matrix composites, Acta Mater. 46 (1998) 11431155. doi:10.1016/S1359-6454(97)00320-0

[38] M. Pahutová, V. Sklenička, K. Kuchařová, J. Březina, M. Svoboda, T. G. Langdon, Creep Strength and Ductility of an AZ Alloy and its Composite, in: E. Aghion, D. Eliezer (Eds.), Proc. $2^{\text {nd }}$ Israeli Int. Conference on Magnesium Science and Technology, Magnesium 2000, Magnesium Research Institute (MRI) Ltd. Beer-Sheva, 2000, pp. 285-292.

[39] H. Riedel, Fracture at High Temperatures, SpringerVerlag Berlin, Heidelberg, 1987. ISBN 0-387-17271-8.

[40] L. N. McCartney, New theoretical model of stress transfer between fibre and matrix in uniaxially fibre reinforced composites, Proc Roy. Soc. Lond. A 425 (1989) 215-244. doi:10.1098/rspa.1989.0104

[41] I.-S. Zhang, High Temperature Deformation and Fracture of Materials, Woodhead Publishing Ltd., Cambridge, 2010. ISBN 978-0-85709-9.

[42] J. Tian, The sources and affecting factors of creep threshold stress of magnesium-based composites, Strength of Materials 48 (2016) 173-182. doi:10.1007/s11223-016-9753-4 